\title{
Management of Utilization and Development of the Production Capacity of the Military-Industrial Complex
}

\author{
Aleksandr Mikhaylovich Batkovskiy ${ }^{1}$ \\ Vladislav Valerievich Klochkov² \\ Elena Georgievna Semenova ${ }^{3}$
}

Alena Vladimirovna Fomina ${ }^{1}$

Natalya Vladimirovna Cherner ${ }^{4}$

\begin{abstract}
1 Joint Stock Company "Central Research Institute of Economy, Management and Information Systems "Electronics" Moscow, Russia

2 V. A. Trapeznikov Institute of Control Sciences, Russian Academy of Sciences, Moscow, Russia ${ }^{3}$ The Department of Innovation and Quality Management, St. Petersburg State University of Aerospace Instrumentation St. Petersburg, Russia

${ }^{4}$ The Department of Industrial Management, Moscow Aviation Institute (National Research University), Moscow, Russia Correspondence: Alexander Mikhailovich Batkovskiy, Central Research Institute of Economy, Management Systems and Information Electronics, Cosmonaut Volkov str. 12, Moscow, 127299, Russia. E-mail: batkovskiy_a@instel.ru
\end{abstract}

\section{Doi:10.5901/mjss.2015.v6n5s4p327}

\section{Abstract}

The article deals with the issue of efficient utilization and development of the production capacity of the military-industrial complex companies comprising integrated structures (mainly, state corporations). This issue is essential for the Russian military-industrial complex which faces the deficit of investment resources and the need for urgent implementation of largescale production plans. The article suggests the ways to assess the resource management's efficiency in the integrated structures' companies, including utilization and development of capacities of specific companies. The production capacitybased integrated indicator of management efficiency (which may be estimated on the basis of directly measurable values) was developed. It shows the potential increase in the integrated structures' production capacities without additional investments, solely due to resource management's enhancement in the member companies. Business tools for improvement in the production capacity management efficiency were also explored. Efficiency indicator was suggested for development of production capacity of the integrated structures' companies, and the optimal principles of selection of investment recipients are explained for 2 scenarios: when complete production cycle is preserved at each company, and when the companies become specialized within integrated structures. Business tools for making optimal investment decisions with regard to information asymmetry and opportunism of companies' managers are described. The analysis allowed to develop the structure and algorithms of integrated structures of the production capacity utilization and development management system on the tactical level (capacities utilization management), the strategic level (capacities development management) and the superstrategic level (capacity maintenance, particularly using the technologies and production capacities of machine tool builders).

Keywords: integrated structures, production capacity, capacity utilization, "bottlenecks", investments, development, efficiency management, coordination, specialization

\section{Introduction}

Most branches of the military-industrial complex operate as part of integrated structures-such as United Aircraft Corporation, United Engine Corporation, Russian Helicopters etc., which comprise previously independent companies as production facilities. On the one hand, this creates new opportunities for utilization of separate companies' capacities, expanding opportunities for efficient allocation of production tasks and investments into development of capacities. However, on the other hand, management of such complex and scattered production systems becomes more complicated due to their large scale and the fact that the interests of the companies' management and personnel differ from the interests of the integrated structures' central body. Integrated structures' management possesses less detailed information on condition and utilization of production capacities of such companies. Therefore, efficient management of 
utilization and development of production capacities of the companies comprising an integrated structure constitutes a serious business issue.

The Russian Federation implements the State Arms Procurement Program (SAP-2020), which stipulates a largescale provision of the Russian Armed Forces with state-of-the-art and next-generation arms and military equipment. The major problem lies in the lack of facilities for production of state-of-the-art and next-generation arms of a new technological level. Limited production facilities cause failures in procurements under the state defense order, which results in top-level criticism of management of the military-industrial complex and integrated structures (Golenishchev, 2014; Kazakov, 2012).

Efficient utilization and development of production capacities is aggravated by the fact that most equipment needed for upgrade of the companies' facilities has been imported, and the manufacturers' countries may initiate import restrictions. Even before the sanctions were imposed against Russia, domestic companies experienced certain problems with access to state-of-the-art technologies and equipment in international markets, especially when such technologies or equipment could be used for manufacturing of military products. In such circumstances, underutilization of state-of-the-art production capacities, inefficient (excessive) investment programs become even more unacceptable, and the search for resources required for utilization efficiency enhancement and development of facilities of the military-industrial complex companies gets high priority.

\section{Literature Review}

In traditional literature on industrial economics, operation of production facilities etc., efficient utilization of the companies' production capacities was measured, first of all, based on the capacities utilization ratio and the return on assets ratio (Asaul et al., 2007; Cantor et al., 2002; Volkov \& Devyatkin, 2004). Production capacity development efficiency was usually measured within the context of investment project efficiency assessment (Vilensky et al., 2004). At the same time, integrated structures include many companies, which, in turn, have numerous facilities (production areas) with quite different capacity utilization levels. Besides, underutilization of production facilities may be conditional upon objective factors, and even necessary. The reserves of production facilities allow to complete orders in unstable environments, minimize waiting periods (Suri, 1998, 2010), etc.

Therefore, the above numerous studies on industrial economics and production facilities operation estimated efficiency of production capacity utilization without special emphasis on the importance of management of this process. We suggest to emphasize and to provide a quantitative assessment of the contribution of resource management in the integrated structures' companies to the efficiency of their utilization and development. The studies of production management usually focus on unitary enterprises and the "bottlenecks" therein (Almstrom \& Kinnander, 2011), while the Russian military-industrial complex is described by scattered organizations, the 'central body' of which does not possess complete information about the condition and utilization of capacities of companies, considering them as 'black boxes'. Such issues were investigated in respect of engineering systems (Aguilera, Mogul, \& Wiener et al., 2003).

This article focuses on the strategic aspects of management of the integrated structure's production capacities without analysis of specific ways of elaboration of optimal solutions, which were explored by a number of authors (Lim \& Chan, 2012; Parekh, Jung, \& Swint et al., 2006). Since this article deals with the issue of management of business and even social-economic systems, rather than engineering ones, the issues of motivation of participants of production and investment processes at all levels-from companies and integrated structures in general down to employees, managers of all tiers-are of the utmost importance. Factoring of the managed entities' own interests is a distinctive feature of the management theory in social and economic systems. This theory includes such productive research areas as the active systems theory (Burkov \& Novikov, 1999; Novikov, 2005; Novikov \& Ivaschenko, 2006). Common business tools for management in case of diverging interests are studied within this field, and this work suggests to use relevant recommendations for solving the problem of development of an efficient system to manage production capacities within integrated structures.

\section{Methods}

\subsection{Hypotheses and the Research Plan}

According to the traditional definition (Ansoff, 2007; Kleiner, 2008; Trenyev, 2000), tactical management means management of production capacity utilization, which includes:

- Selection of a production plan within existing capacity restrictions; 
- Management of production capacity utilization, i.e., allocation of works and orders among production subdivisions, areas, equipment units etc.;

- Management of utilization of temporarily idle capacities (including mothballing, conversion to manufacturing of other products, etc.).

We suggest to developing an efficiency criterion for management of integrated structure's production capacity utilization by comparing the total capacity of integrated structure's companies with full capacity utilization. We have pointed out to existence of excessive, economically justified production capacities. That's why inefficient production capacity utilization implies significant (more than 10 percent) permanent underutilization thereof in the long run (a year and more), without account for unavoidable short-term fluctuations in production facilities utilization.

Strategic management of a company means management of the capacity, including the production capacity, i.e., facilities development management. Generally, the following types of management actions may be applied in this field:

- Selection of amounts and allocation (among companies and their facilities) of investments into creation, upgrade and expansion of production facilities,

- Selection of technologies and equipment.

In this field, efficiency indicators need to be elaborated for management of the production capacity development in respect of individual companies and the integrated structure in general.

Upon completion of the analysis of the factors influencing the efficiency of management of utilization and development of the production capacity of the military-industrial complex companies, the structure and the algorithm of relevant management system's operation may be explained.

\subsection{Assessment of the Efficiency of Production Capacity Utilization Management in Respect of Integrated Structures' Companies}

Let's analyze an integrated structure, which includes companies (plants, production sites) $i=1,2, \ldots$ n. Generally, such companies within the integrated structure may possess several types of facilities (production areas) marked with indices $j=1,2, \ldots \mathrm{m}$. While the Russian military-industrial complex is dominated by full production cycle companies, most such companies have almost all types of facilities pertaining to relevant industries-blank (foundry, forging etc.), machine processing and other physico-chemical types of parts processing (laser, electrical discharge machining etc.), coating and thermal processing, assembling facilities. As companies shift towards the matrix- and network-based organizational structures, which are typical for high-tech industries of the most developed countries, the companies' specialization and fragmentation of production chains come into play. However, this is also the case when production areas may be singled out within a specialized company. For example, machine processing includes several types of facilities, which, in general, may require various types of equipment, specialists with various skills etc. Further fragmentation may be inexpedient even within the network- and matrix-based organizations-however, reforming of the organizational structure of the military-industrial complex is not a matter of interest within this study. The organizational structure of an integrated structure is described above (production sites $i=1,2, \ldots \mathrm{n}$ with facilities (production areas) on each of them $j=1,2, \ldots \mathrm{m}$ ). The focus here is on management of this structure and the issues of efficient utilization and development of the above companies' facilities. In turn, it is not significant for our analysis whether such integrated structure is in a form of "hard" integration (like holding companies and industrial corporations existing at the moment), or "soft" integration, voluntary association of independent companies for the purpose of implementation of a specific project, known as the "virtual production association".

Let capacity of $j_{\text {th }}$ facilities type of $i_{\text {th }}$ company equal to ${ }^{v_{j}^{i}}$ knock-down kits per year. Then capacity of $i_{\text {th }}$ company $v^{i}$ is defined by its 'bottleneck', i.e.,

$$
v^{i}=\min _{j} v_{j}^{i}, i=1,2, \ldots \mathrm{n}
$$

In turn, the total capacity of the integrated structure $V^{\text {uc }}$ equals to the sum of capacities of its companies:

$$
V^{\text {uC }}=\sum_{i=1}^{n} v^{i}=\sum_{i=1}^{n} \min _{j} v_{j}^{i}
$$

At the same time, if coordinated tactical management is carried out on the integrated structure's level (i.e. management of production capacity utilization), the production capacity of an integrated structure may significantly exceed the above level $V^{\text {ис }}$. The "bottlenecks" of individual companies may be compensated on the integrated structure's level, engaging existing capacities of other companies. Ideally, the total capacity of relevant type of facilities $v_{j}$ should be available to the integrated structure's management: 


$$
v_{j}=\sum_{i=1}^{n} v_{j}^{i}, j=1,2, \ldots \mathrm{m}
$$

Obviously, "bottlenecks" will exist in this case too, though on the level of the integrated structure, and its maximum production capacity will be determined by the total capacity of the most 'deficient' facility type:

$$
\widehat{V}^{\mathrm{uC}}=\min _{j} v_{j}=\min _{j} \sum_{i=1}^{n} v_{j}^{i}
$$

This value is admittedly larger (save for the unlikely situation of absolutely balanced capacities of all facilities at all companies of the integrated structure) than the above estimated integrated structure's capacity:

$$
\widehat{V}^{\text {UC }}=\min _{j} \sum_{i=1}^{n} v_{j}^{i}>\sum_{i=1}^{n} \min _{j} v_{j}^{i}=V^{\text {UC }}
$$

As the minimum of sums of different values is larger than the sum of minimums.

In practice, coordinated management of production capacities within integrated structures almost does not exist in the national military-industrial complex due to complexity of assessment of the capacities of companies' individual facilities on the integrated structure's level, high labor costs of production capacity assessment in the absence of companies' electronic certification (Manturov \& Klochkov, 2012)). Though some companies do not conceal their production capacities from the integrated structure's management, existing cognitive capabilities pertaining to management of large-scale production systems are usually described by the absence of top management's detailed idea of the companies' production capacities, up to the capacities of relevant production areas. Management of integrated structures sees companies as 'black boxes' with known total capacity reported by management of such companies ${ }^{v_{j}}$, $j=1,2, \ldots$ m. Elaboration of "bottlenecks" at the integrated structure's level may be possible only after radical modernization of the industry's production management system on the basis of up-to-date information technologies, including corporate information systems, enterprise resource planning, enterprise electronic certification and physical stocktaking of fixed assets, which will make possible the real-time monitoring of availability and condition of such fixed assets, as well as utilization of each type of facilities at each company.

In a best-case scenario, the companies will provide to the integrated structure's management summary information about their production capacities in the form of their capacity levels $\left\{v^{i}\right\}$. If production facilities utilization in integrated structures is managed based on detailed information about capacities and their utilization, production areas, the integrated structures' total capacity would increase from $V^{\text {uC }}$ to $\widehat{V}^{\text {uC }}$. Therefore, $\bar{V}^{\text {uC }}$ ratio shows the potential increase in the integrated structure's production capacity without additional investments- solely due to enhancement of the tactical management, i.e. management of production capacity utilization. Obviously, this is the theoretical upper limit of production capacities of the integrated structure's companies, which is hardly achievable in practice, even after enhancement of management-at least because intermediate products would have to be shifted between production areas between companies in order to achieve such level, which would not be expedient due to resulting shipment, transaction and other costs of such shift. Still, it would be useful to estimate $\widehat{V}^{\text {hC }}$ level in order to get an idea of potential benefits from enhancement of production capacity utilization efficiency.

May $\frac{\widehat{V}^{\text {uC }}}{V^{\text {uC }}}$ ratio are labor-consuming and expensive (Manturov \& Klochkov, 2012) due to the absence of companies' electronic certification and the real-time integrated information systems) statistical surveys of the integrated structure's companies assess capacity utilization ratios (sometimes even with elaboration up to the level of individual facilities). Let's denote the utilization ratio of $j_{\text {th }}$ facilities type of $i_{\text {th }}$ company as $k_{j}^{i}, i=1,2, \ldots \mathrm{n}, j=1,2, \ldots \mathrm{m}$. It equals to the ratio of output of such facility $q_{j}^{i}$ to its capacity:

$$
k_{j}^{i}=\frac{q_{j}^{i}}{v_{j}^{i}}, i=1,2, \ldots \mathrm{n}, j=1,2, \ldots \mathrm{m}
$$

where the output of all facilities of such company, if the companies' reserve capacity is not utilized on the integrated structure's level, will be as follows:

$$
q_{j}^{i} \equiv q^{i}, i=1,2, \ldots \mathrm{n}, j=1,2, \ldots \mathrm{m}
$$


Then the average ratio of capacity utilization of $j_{\text {th }}$ type of facilities in the observed companies (industry, subindustry, integrated structure) will be as follows:

$$
\bar{k}_{j}=\frac{q_{j}}{v_{j}}, j=1,2, \ldots \mathrm{m}
$$

where ${ }^{q_{j}=\sum_{i=1}^{n} q_{j}^{i}}$ means the total output of $j$ th type of facilities within the integrated structure. If the companies of this integrated structure (sub-industry, industry) make final products without exporting and importing components and production services, then the outputs of all types of facilities would be identical and just equal to the integrated structure's output:

$$
q_{1}=q_{2}=\ldots=q_{m}=q^{\mathrm{UC}}=\sum_{i=1}^{n} q^{i} .
$$

This means that the average ratio of capacity utilization of $j$ th type of facilities in the integrated structure's companies may be expressed as follows:

$$
\bar{k}_{j}=\frac{q_{j}}{v_{j}}=\frac{q^{\mathrm{UC}}}{v_{j}}, j=1,2, \ldots \mathrm{m}
$$

Then the total capacity of $j_{\text {th }}$ type of the integrated structure's companies may be expressed through average utilization ratio of such type of facilities:

$$
v_{j}=\frac{q^{\mathrm{uC}}}{\bar{k}_{j}}, j=1,2, \ldots \mathrm{m}
$$

Since the achievable level of the integrated structure's production capacity is limited by the total capacity (which is minimal for all types of facilities), as shown above, it may be assessed using the known total output of the integrated structure and the average utilization ratio of capacities of certain types of facilities, based on the following formula:

$$
\hat{V}^{\text {UC }}=\min _{j} v_{j}=q^{\text {UC }} \cdot \min _{j} \frac{1}{\bar{k}_{j}}=\frac{q^{\text {UC }}}{\max _{j} \bar{k}_{j}}
$$

At the same time, companies may also report integral utilization ratios in respect of their facilities $\left\{k^{i}\right\}$, determined as ratios of their output to their total capacities (limited by the "bottlenecks" of certain companies):

$$
k^{i}=\frac{q^{i}}{v^{i}}, i=1,2, \ldots \mathrm{n}
$$

Then the total output of the integrated structures may be expressed as:

$$
q^{\text {UC }}=\sum_{i=1}^{n} q^{i}=\sum_{i=1}^{n} k^{i} \cdot v^{i}
$$

In absence of centralized management of capacity reserves at specific facilities comprising the integrated structure, the total capacity of member companies corresponds to the output in case of $100 \%$ utilization of capacity of certain companies, i.e.

$$
V^{\mathrm{UC}}=\sum_{i=1}^{n} v^{i}=\sum_{i=1}^{n} 1 \cdot v^{i}=\left.q^{\text {иС }}\right|_{k^{i} \equiv 1, i=1, \ldots n}
$$

Inserting this expression into the formula for achievable capacity of the integrated structure, we obtain:

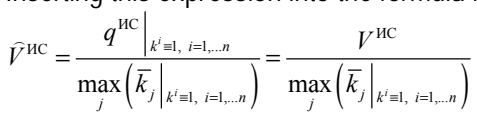

where $\left.\bar{k}_{j}\right|_{k^{i}=1, i=1, \ldots . . n}$ is the average ratio of capacity utilization of $j_{\text {th }}$ type of facilities in the integrated structure's companies, with $100 \%$ utilization of capacities of certain companies. Therefore, when the centralized management of capacity reserves of certain facilities comprising the integrated structure is implemented, the total capacity of member companies may increase by the following number of times: 


$$
\frac{\hat{V}^{\mathrm{UC}}}{V^{\mathrm{UC}}}=\frac{1}{\max _{j}\left(\left.\bar{k}_{j}\right|_{k^{i} \equiv 1, i=1, \ldots n}\right)}
$$

That is, the achievable relative growth of capacity is inversely related to the maximum average (for the integrated structure's companies) utilization ratio of certain types of facilities. This value describes the efficiency of production capacity management in respect of the integrated structure's companies. The higher the value of $\frac{\widehat{V}^{\text {uC }}}{V^{\text {uC }}}$ (and, respectively, the lower the value of $\max _{j}\left(\left.\bar{k}_{j}\right|_{k^{i}=1, i=1, \ldots, n}\right)$, the higher the management enhancement reserves.

\subsection{Assessment of the Efficiency of Production Capacity Development Management in Respect of Integrated Structures' Companies}

If existing capacity of a company or an integrated structure is not sufficient for implementation of production plans, capacity may be increased as part of strategic management, which would require relevant investments. Their efficiency may be assessed by their impact on the production capacity level.

As shown above, the integrated structure's capacity may be increased by $\frac{\widehat{V}^{\text {UC }}}{V^{\text {UC }}}$ times without investments in fixed assets, i.e. without purchase of equipment, construction of new buildings and premises etc., solely due to enhancement of resource management in the integrate structure's companies. Naturally, this would also require investments-mostly in management information systems, which allow to switch between capacities of certain companies in the real-time mode. Still, in the absence of centralized resource management in the integrated structures' companies, increase in capacities even against $V^{\text {UC }}$ level would require investments. Their volume depends on certain principles applied in planning of production capacity development. They may differ by the degree of expediency-even in the absence of the above centralized resource management at the companies.

When the management of companies informs the integrated structure's management of the total production capacity $\left\{v^{i}\right\}, i=1,2, \ldots \mathrm{n}$, usually it has an idea of its company's 'bottlenecks'. And if a decision to increase production capacity of $i_{\text {th }}$ company up to $v^{i^{\prime}}=v^{i}+\Delta v^{i}$ level is made at the integrated structure's level, development of the company's production capacity may be planned in the most cost-efficient way, primarily through elimination of existing "bottlenecks". Minimum investments for ith company required for the planned capacity increase may be presented as follows:

$$
\Delta \breve{I}^{i}\left(\Delta v^{i}\right)=\sum_{j=1}^{m} b_{j}^{i} \cdot \max \left\{0 ;\left(v^{\prime}-v_{j}^{i}\right)\right\}, i=1,2, \ldots \mathrm{n}
$$

where $b_{j}^{i}$ is the capital output ratio of $j_{\text {th }}$ type of facilities at $i_{\text {th }}$ company (strictly speaking, capital output ratios may be different at different companies- even due to individual conditions of major construction operations in various regions, as well as different technologies which should be applied depending on the company's production volumes). The average capital output ratio of each company in case of increase in its capacity by $\Delta v^{i}$ (where not only capacity increase $\Delta v^{i}$, but the original capacity level $v^{i}$ do matter) may be assessed as an integrated indicator of efficiency of development of the companies' facilities:

$$
\bar{b}^{i}\left(\Delta v^{i}\right)=\frac{\Delta I^{i}\left(\Delta v^{i}\right)}{\Delta v^{i}}, i=1,2, \ldots \mathrm{n},
$$

provided that the requested investment $\Delta I^{i}\left(\Delta v^{i}\right)$ does not always correspond to the previously estimated minimum possible value $\Delta I^{i}\left(\Delta v^{i}\right)$. In principle, the companies' management may request investments in such manner in order to increase (on pro rata basis) the capacity of all facilities by $\Delta v^{i}$, then

$$
\Delta I^{i}\left(\Delta v^{i}\right)=\Delta v^{i} \cdot \sum_{j=1}^{m} b_{j}^{i}, i=1,2, \ldots \mathrm{n}
$$

the average capital output ratio of $i$ th company will be equal to 


$$
\bar{b}^{i}\left(\Delta v^{i}\right)=\frac{\Delta I^{i}\left(\Delta v^{i}\right)}{\Delta v^{i}}=\sum_{j=1}^{m} b_{j}^{i}
$$

i.e, the sum of the capital output ratios of certain facilities within such company. This value may be treated as the average capital output ratio in case of balanced, i.e. proportional development of capacities of all types of facilities. And even in case of efficient planning of facilities development, the average capital output ratio of the company would reach this value after elimination of all "bottlenecks" and equalization of capacities of all facilities. However, prior to that, with efficient investment planning, the average capital output ratio should be lower, because not all facilities in the company need to be expanded at the same time. With existing obvious 'bottlenecks', the difference between the described investment amounts may be significant.

\subsection{Production Capacity Development Optimization for the Integrated Structures' Companies}

On the level of integrated structures, optimization tasks may be set in respect of investment allocation of the following type:

$$
\Delta I^{\mathrm{uC}}=\sum_{i=1}^{n} \Delta I^{i}\left(\Delta v^{i}\right) \rightarrow \min _{\left\{\Delta v^{n}\right\}} \mid \sum_{i=1}^{n} \Delta v^{i}=\Delta V^{\mathrm{uC}}
$$

i.e., the planned total increase in the integrated structure's capacity should be achieved, if possible, with minimum investments. Strictly speaking, in the high-tech industry, the investments in development of the companies' production capacities cannot be used as a generalizing criterion in decision making, at least because there are more important (in addition to investments in fixed assets) elements in the output's cost structure-labor and material costs. And it is quite possible that the option of production capacity development which requires minimum investments will not be efficient even based on the total costs minimization criterion (though cost minimization is not a correct decision making objective in the high-tech industry-market entry timing and quality maintenance factors are important as well). Higher investment costs may be compensated by lower average variable costs at the production phase-due to decrease in labor input and consumption of materials. At the same time, the required investment may be a critical indicator in case of deficit of financial and physical capital; i.e., sometimes the supply of necessary equipment is restricted due to implications of the foreign policy or the difficulties faced by the Russian machine tool builders.

As shown above, the average capital output ratio of companies $\overline{b^{i}}$ would change with increase in their capacity as follows: first of all, prior to complete elimination of all 'bottlenecks', the capital output ratio should be lower than the total amount of capital output ratios of individual facilities $\sum_{j=1}^{m} b_{j}^{i}$, and then the capital output ratio should become equal to this amount when the capacities of all the types of facilities are balanced:

$$
\forall i=1,2, \ldots n: \bar{b}^{i}\left(\Delta v^{i}\right)=\left\{\begin{array}{c}
<\sum_{j=1}^{m} b_{j}^{i}, \exists j: v_{j}^{i}>v^{i} \\
\sum_{j=1}^{m} b_{j}^{i}, v_{1}^{i}=v_{2}^{i}=\ldots=v_{m}^{i}=v^{i}
\end{array}\right.
$$

\section{Results}

\subsection{Assessment of Production Capacity Utilization Efficiency in the Aircraft Engine Building Industry}

In order to demonstrate the application of the method described in clause 3.2, let's make an estimate based on available data on production capacities and their utilization in the aircraft engine building industry in 2007. The estimate was based on the data specified in the annual reports of joint-stock companies and relevant certificates. First of all, we calculated the levels of utilization of each type of equipment (in turn, these types of equipment may be referred to specific facilities, production areas of engine builders) in sub-industry's companies in 2007. Summary of the results showed that in 2007 the average utilization of the equipment by Russian aircraft engine builders corresponded to the ranges described in Table 1. 
Table 1. Ranges of average utilization of different types of equipment by aircraft engine builders in 2007 (\%)

\begin{tabular}{lccc}
\hline Equipment type/company type & Production facilities & Designers & Assembly facilities \\
\hline Metal cutting & $33.9-62.0$ & $40.0-100.0$ & $42.0-90.0$ \\
Forging and pressing & $34.1-40.0$ & $15.0-50.0$ & $25.0-74.0$ \\
Foundry & $34.3-86.0$ & 60.0 & $28.0-50.0$ \\
Welding & $34.2-54.0$ & $30.0-90.0$ & $10.0-56.0$ \\
Assembly and installation & 50.0 & $40.0-76.0$ & $30.0-50.0$ \\
For processing of non-metals & 33.6 & 50.0 & $30.0-62.0$ \\
For thermal processing & $33.9-95.0$ & $60.0-90.0$ & $42.0-80.0$ \\
Plating & $33.8-90.0$ & 65.0 & $40.0-94.0$ \\
Measuring & $80.0-93.0$ & $50.0-90.0$ & $43.0-88.0$ \\
Test bench & 15.0 & $30.0-50.0$ & $25.0-92.0$ \\
Other & $80.0-90.0$ & 30.0 & $32.0-60.0$ \\
\hline
\end{tabular}

Figure 1 provides data on average utilization of different types of equipment within the sub-industry. For the avoidance of misrepresentation of weighted average values, only those companies, in respect of which information on utilization of the listed equipment type is available, were taken into account.

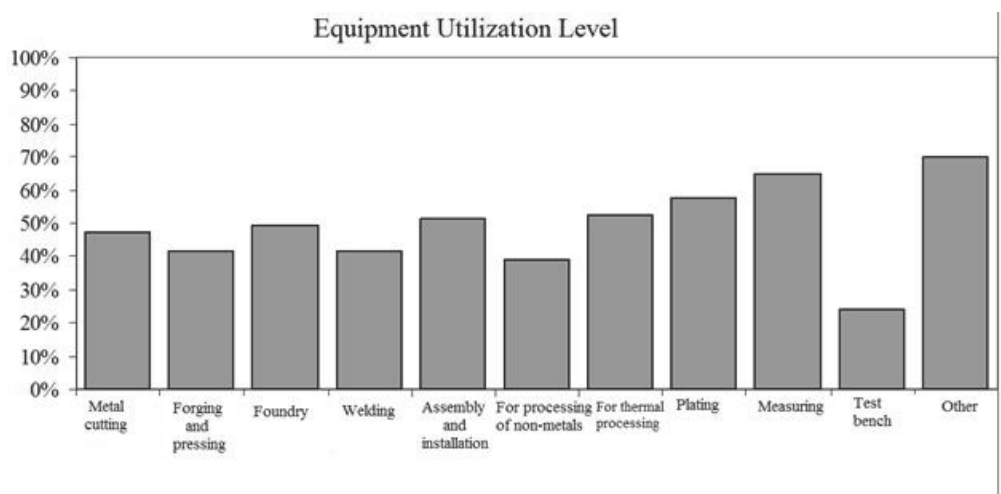

Figure 1. Weighted average level of utilization of different types of equipment by aircraft engine builders in 2007

The highest utilization level was observed in respect of measuring equipment (65\%), plating equipment (58\%) and thermal processing equipment (53\%). Therefore, with perfect management of capacity reserves at certain facilities within the integrated structure's companies, output could be increased by $\frac{1}{0.65}$ times, i.e. by $54 \%$. Due to elimination of "bottlenecks" on the integrated structure's level, total capacity could be increased by $\frac{1}{0.58}$ times, i.e., by $72 \%$ (after increase in the measuring equipment's capacity), then by $\frac{1}{0.53}$ times, i.e., by $89 \%$ (after increase in the plating facilities' capacity), etc.

Using the tools proposed herein and based on actual source data, we may assess the efficiency of production capacity utilization by companies and integrated structures of various industries of the military-industrial complex.

\subsection{The Structure and Algorithms of Efficient Management of Production Capacity Development and Utilization by the Military-industrial Complex}

This section describes the structure of management of production capacity development and utilization management by the military-industrial complex, with implementation of the above principles of efficient management. This management system should cover various management levels-tactical, strategic, super-strategic. Each management loop should provide for feedbacks in order to ensure sustainability of management in an unstable and significantly unpredictable environment. 


\subsubsection{The Tactical Management Loop for Production Capacity Utilization by the Integrated Structures' Companies}

On the tactical level (capacity utilization management) we need to consider management of utilization of the companies' facilities, the structure and specifications of which are assumed to be constant in the short run. The above analysis shows that more efficient utilization of production facilities reserves is possible when the companies' integration benefits are realized to the fullest extent-when certain companies within the integrated structure are not treated by their managers as 'black boxes' with set capacities (limited by "bottlenecks" intrinsic to certain companies), when elaboration is made up to the level of individual facilities, production areas, the utilization management in respect of which would be expedient through switching between various production assignments within integrated structures. In order to do this, we need to possess (in addition to detailed information on available fixed assets and specifications of equipment) the real-time data on equipment's technical condition and utilization. Obviously, such recommendations may be implemented only within a comprehensive information system of companies of the military-industrial complex, including electronic certification of fixed assets and-in the future-integration of resource management systems of the integrated structure's companies. Figure 2 shows the flow chart of the tactical management loop's operation algorithm pertaining to utilization of production capacities by the integrated structures' companies, which implement the above principles and procedures.

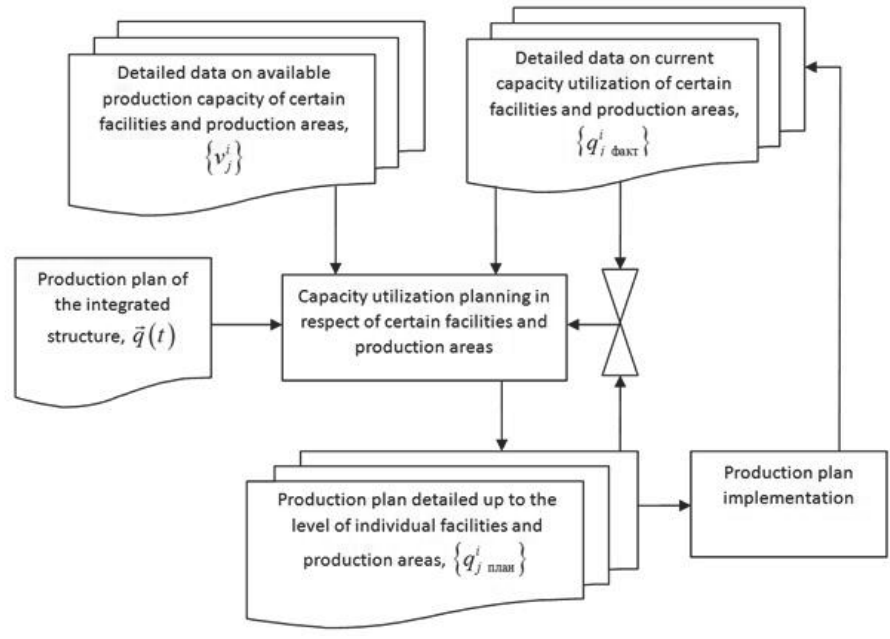

Figure 2. Tactical management loop in respect of utilization of facilities by the companies of the military-industrial complex and integrated structure.

\subsubsection{Strategic Management Loop in Respect of Utilization and Development of Facilities by the Companies of the Military-industrial Complex and Integrated Structures}

Facilities development management should be considered, first of all, on the strategic level (i.e., on the level of management of the companies' capacities). At the same time, the issues of efficient utilization of the companies' production capacities are solved as part of strategic management when the company's product or market strategy is selected. When developing strategic production plans for the companies of the military-industrial complex and integrated structures, existing production capacities of individual companies and facilities should be taken into account. Accounting for the previously created production facilities and projected investments for their development may significantly affect the optimal selection of the product range, planned production volumes and prices, i.e. the companies' product and market strategies. Therefore, as part of the strategic development, the long-term production plan should not be treated as a rigidly fixed plan. Of course, production plans implemented under the state defense order, must be implemented within specified deadlines. However, drafting the State Arms Procurement Program (which also relates to the strategic level) requires and makes possible its optimization with account for the production aspects on the basis of relevant military and economic calculations. Strategic management of facilities utilization and development is an element of strategic 
management in the companies of the military-industrial complex and integrated structures. On this level, we need to ensure cost- and time-efficient development of the companies' facilities and motivation of:

- The companies' management to inform the integrated structures' management about the actual investment requirements, avoiding overestimations;

- Employees and mid-level managers to implement (in an efficient manner) innovative technologies and stateof-the-art equipment in order to increase labor productivity.

- In order to achieve these goals, competition-based mechanisms of allocation within the integrated structures may be efficient with regard to:

- Investment resources;

- Production orders.

For the avoidance of unnecessary delays with implementation of investment projects in respect of the companies' facilities development, control of the companies' managers (as regards selection and acquisition of production equipment and other measures aimed at development of relevant facilities) should be based on the final result, i.e. the total costs of facilities development and the time when production facilities are ready for fulfillment of production tasks. These are the summarizing indicators, for which managers of companies of the military-industrial complex should assume responsibility given the present volatile environment and enhancement in the role of temporal factors.

Figure 3 shows a flow chart of the strategic management loop's operation algorithm in respect of utilization and development of facilities by companies of the military-industrial complex and integrated structures.

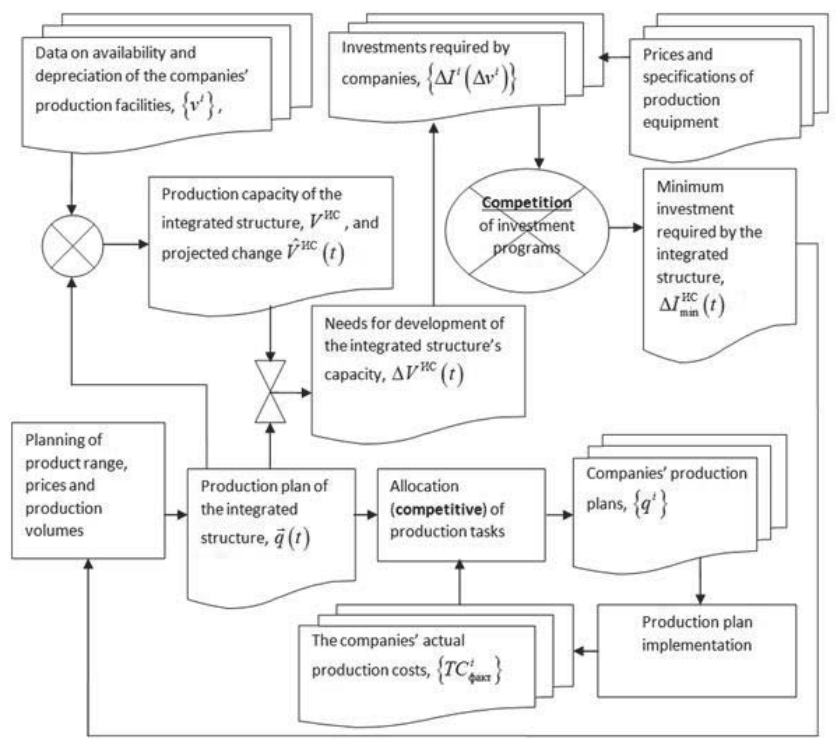

Figure 3. Strategic management loop in respect of utilization and development of facilities by the companies of the military-industrial complex and integrated structures

\subsubsection{Super-strategic Mnagement Loop in Respect of Development of the Military-industrial Complex Production Capacity}

Reduction in the time required for creation and implementation of innovative technologies in the high-tech industry requires integration of research and development and technological preparation for production, i.e.,:

- Research and development for creation of promising high-tech products;

- Development of new production technologies, designing of high-tech production equipment.

In order to implement such integrated management, cooperation between relevant specialists of the militaryindustrial complex and machine tool builders needs to be established in order to resolve relevant issues related to production of state-of-the-art (( $\mathrm{N}+2)$ th (where $\mathrm{N}$ is the current generation)) product generation. Therefore, technological 
development of machine tool builders is determined by prospective needs of the military-industrial complex companies. Labykin (Labykin, 2014) and Mechanic (Mechanic, 2014) argue that only such direct cooperation between machine builders and machine tool builders would allow to overcome the machine tool building industry's crisis in Russia, reduce its development risks to an acceptable level (given the small scale of the Russian market).

Since the machine tool building industry ensures maintenance and development of production capacities of the military-industrial complex, specialists working for this complex and who are involved in drafting of the machine tool building industry's development strategy, manage maintenance of capacities of their own industry, which relates to the super-strategic management (Kleiner, 2008; Trenyev, 2000). Figure 4 shows the super-strategic management loop in respect of development of the military-industrial complex companies (in respect of development of their facilities).

Actually, it intersects the strategic management loop in respect of development of the machine tool building industry (which corresponds to treatment of super-strategic management of the military-industrial complex companies as management of capacity maintenance tools).

The outrunning nature of development of required production technologies and promising models of production equipment ensures their availability by the start of preparation of fixed assets for manufacturing of state-of-the-art products. Otherwise, if time-consistent planning of technological development of the machine tool building industry and the military-industrial complex is replaced with situational response, delays for several years in manufacturing of state-ofthe-art products will be inevitable. Therefore, efficiency of super-strategic management of development of production capacity of the military-industrial complex companies may be assessed on the basis of the estimated effect of earlier release of state-of-the-art products into the market (or estimated losses incurred due to relevant delay).

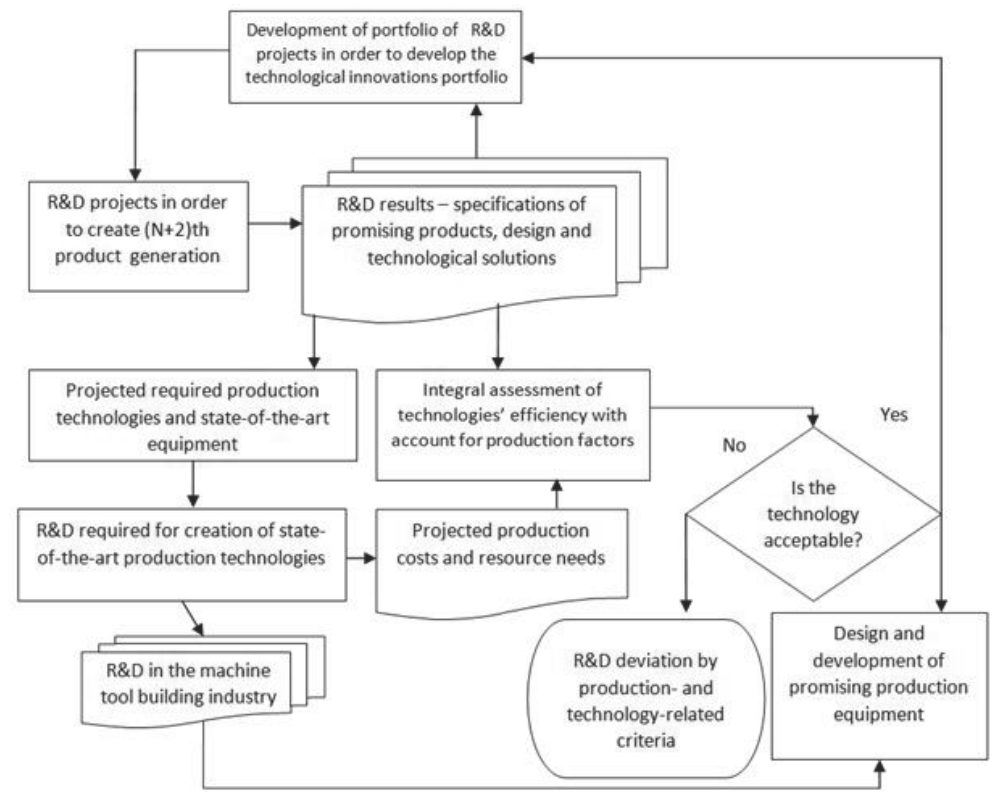

Figure 4. Super-strategic management loop in respect of innovative technological development of the military-industrial complex production capacity

Since the technology used in manufacturing of state-of-the-art products and relevant production costs may be unknown at the development phase, it is necessary to maintain the feedback between development of new technologies and production equipment, and development of state-of-the-art products. The latter should be designed based on projected production costs and the timeframes for creation of necessary technologies and equipment, implementing the principle of design with pre-set costs. 


\section{Discussion}

Clause 3.4 shows that the incremental capital output ratio for an individual company cannot exceed the sum of the capital output ratios of all facilities $\sum_{j=1}^{m} b_{j}^{i}$, being able to come close to this level (which corresponds to proportional development of capacities of all facilities) only after elimination of 'bottlenecks'. However, the practice of development of integrated structures within the Russian military-industrial complex shows that it is typical for management of integrated structures' companies to overstate the required investments for expansion of production capacities. Quite often, development of some types of facilities does not result in growth of the company's overall production capacity. According to the network planning theory, which is fundamental for studying the production operations management (Burenok et. al., 2006; Stevenson, 2005; Taha, 2006), facilities under development are not located on the critical path of such company, i.e., they do not set the timeframes for fulfillment of orders, and, eventually, for the company's production capacity.

Overstatement of requested investments may point out both to inefficient management of production capacity development within a company (due to restricted expediency, lack of information and cognitive capabilities of utilization thereof-similar to the above described issue for integrated structures), and also to conscious opportunism. In such case, the competition-based method of investment allocation within the integrated structure (shown in Figure 3) may be an efficient tool against opportunism. Assignment of the optimization task specified in clause 3.4 corresponds to such method. Its solution comes down to selection of such companies (as recipients of investments), which would generate the set capacity growth level with the least investments. In turn, it means, first of all, elimination of the 'cheapest' "bottlenecks" within such integrated structure. Besides, such competition-based method contributes to equalization of capacities of the companies' facilities.

At the same time, under the currently implemented concept of the Russian high-tech industry's restructuring (see (Gosudarsvennaya programma..., a), (Gosudarsvennaya programma..., b)), the goal should rather include companies' specialization (which, obviously, would result in strictly disproportional development of production areas' capacities) than equalization of capacities of all facilities with preservation of complete production cycle in the companies. However, efficient specialization of production sites within integrated structures also requires centralized capacity management in respect of facilities on the integrated structures' level, which is (as shown above) the main way to improve production capacity utilization efficiency of the military-industrial complex companies at its current development phase. In this case we may also set the goal of optimal selection of the companies' specialization within integrated structures. The important factors affecting selection include the levels of already created production facilities of certain production areas, as well as incremental capital output ratios of relevant types of facilities in different companies. Significant state-of-the-art capacities possessed by a company for a certain type of products and low values of incremental capital output ratios facilitate selection of such company as a center of competence specialized (within an integrated structure) on manufacturing of relevant components or production services. However, again, it would not be correct to focus solely on comparison of investment costs. Integrated indicators of efficiency of investment projects (focusing on development of the company's facilities) should be compared.

\section{Conclusion}

1) Efficient utilization of production capacities of the military-industrial complex companies (which are combined in integrated structures) depends on centralized resource management (at the integrated structure's level) in member companies, particularly through utilization of capacities of individual companies. When such opportunity emerges, relative growth of the integrated structure's total capacity may achieve the value, which is reciprocal to the average load factor of the most utilized type of production facility within such integrated structure.

2) As demonstrated by Russian aircraft engine builders, $40-60 \%$ increase in the total production capacity of the sub-industry could be achieved in 2008 without investments in construction and new production equipment.

3) Electronic certification of companies and availability of information systems (corporate information systems, ERP-systems), which make possible the real-time monitoring of availability, good working condition and utilization of each type of facilities at each company, are the pre-conditions of efficient resource management in the integrated structures' companies.

4) Efficient management of facilities development by the military-industrial complex companies may be assessed using the company's average incremental capital output ratio, which is equal to ratio of investments to relevant growth in production capacities. In case of obvious "bottlenecks" in the company, the incremental capital 
output ratio may be several times lower than the value of relevant balanced proportionate development of all types of the company's facilities (being equal to the sum of all capital output ratios of all types of the company's facilities). With improvement in the capacities' balance, the incremental capital output ratio would increase up to the above value. Situation when such level is exceeded by the incremental capital output ratio points out to disproportionate capacity development in this company.

5) Within an integrated structure, it would be reasonable to set the task of optimal allocation of investments among the companies; such task may solved as follows:

- If original facilities are maintained within each company, investment resources should be allocated first of all among the companies with the least incremental capital output ratio, i.e. where elimination of "bottlenecks" is the least expensive;

- If the companies' internal production structure may be managed on the integral structure's level, it would be reasonable to focus on such production facilities, for which total production costs would be the smallest in case of allocation to this company.

\section{Acknowledgements}

This research project was supported by the Russian Scientific Fund (RSF Project No. 14-18-00519).

\section{References}

Aguilera, M. K., Mogul, J. C., \& Wiener, J. L., et al. (2003). Performance debugging for distributed systems of black boxes. In Proceedings of the Nineteenth ACM Symposium on Operating Systems Principles (pp. 74-89). ACM Press.

Almstrom, P., \& Kinnander, A. (2011). The productivity potential assessment method: Assessing and benchmarking the improvement potential in manufacturing systems at shop-floor level. International Journal of Productivity and Performance Management, $60(7), 758-770$.

Ansoff, I. (2007). Strategic management. Houndmills, Basingstoke. Hampshire: Palgrave Macmillan.

Asaul, A. N., Starinsky, V. N., \& Bezdudnaya, A. G., et al. (2007). Evaluation of machinery, equipment and vehicles. Saint-Petersburg: "Gumanistika".

Burenok, V. M., Lavrenov, G. A., \& Khrustalev, E.Y. (2006). Mechanisms of production of military products. Moscow: Nauka.

Burkov, V. N., \& Novikov, D. A. (1999). The theory of active systems: Status and prospects. Moscow: Synteg.

Cantor, Y. L., Ginzburg, A. I., \& Cantor, V. E. (2002). Fixed assets of industrial enterprises: A manual. Saint-Petersburg: Piter.

Golenishchev, A. (2014). Enterprize Leaders, breaking the state defense order, will be disqualified. Gazeta "Izvestiya" newspaper.

State Program of the Russian Federation "Development of the Aviation Industry in the 2013-2025 Years. Retrieved from http://www.minpromtorg.gov.ru/ministry/fcp/avia2013-2025

State Program of the Russian Federation "Development of the Ship Building Industry in the 2013-2030 Years. Retrieved from http://old.minpromtorg.gov.ru/ministry/fcp/6/suda.doc

Kazakov, A. (2012). Military Industrialists' Headache. Voenno-promyshlenny courier-Military-industrial digest, 1, 418.

Kleiner, G. B. (2008). The enterprize strategy. Moscow: Delo.

Labykin, A. (2014). The machine-tool construction Renaissance. Expert Online (the $17^{\text {th }}$ of June, 2014).

Lim, M. K., \& Chan, H. K. (2012). Optimize resource utilization at multi-site facilities with agent technology. Paper presented at Int. Conf. Advances in Production Management Systems (pp. 503-510), Rhodes, Greece.

Manturov, D. V., \& Klochkov, V. V. (2012). A system of the aviation industry production programs' feasibility Forecasting and ensuring. Vestnik MAI, 19, 1.

Mechanik, A. (2014). KWho will produce the Russian spindle. Expert magazine, 28, 907.

Novikov, D. A. (2005). Organization systems' control theoty. Moscow: MPSI.

Novikov, D. A., \& Ivaschenko, A. A. (2006). Firm innovation development organizational management models and methods. Moscow: LENAND.

Parekh, J., Jung, G., \& Swint, G. S., et al. (2006). Issues in Bottleneck Detection in Multi-Tier Enterprise Applications. International Workshop on Quality of Service (pp. 302-303).

Stevenson, W. (2005). Production/Operations Management (8 th ed.). Irwin: McGraw-Hill.

Suri, R. (1998). Quick Response Manufacturing. A Companywide Approach to Reducing Lead Times. Productivity Press.

Suri, R. (2010). It's About Time. The Competitive Advantage of Quick Response Manufacturing. Productivity Press.

Taha, H. A. (2006). Operations Research: An Introduction. Upper Saddle River. NJ: Prentice Hall.

Trenyov, N. N. (2000). Strategic management. Moscow: Prior.

Vilensky, P. L., Livshits, V. N., \& Smolyak, S. A. (2004). Estimating investment projects' efficiency: Theory and practice. Moscow: Delo.

Volkov, O. I., \& Devyatkin, O. V. (2004). Organization of Production of the Enterprise. Moscow: INFRA-M. 